\title{
Perceived Ease of Use, Perceived Usefulness and the Usage of Computerized Accounting Systems: A Performance of Micro and Small Enterprises (MSEs) in China
}

\author{
Zhang Lanlan, Aidi Ahmi, Oluwatoyin Muse Johnson Popoola
}

\begin{abstract}
Computerized Accounting Systems (CAS) has been used as a tool to help the accountants and the business owner to record daily business transactions and produce accounting reports in no time. The adoption of CAS among the users, however, varies especially in term of the factors that influence the usage and the level of the adoption. This paper aims, among other factors, to investigate the relationship between the model of technology acceptance (TAM) and the use of CAS. The main purpose is to examine the connection between the two variables of TAM, perceived ease of use and perceived usefulness, and use of CAS among accountants in micro and small enterprises (MSEs). The scope of this study is businesses in Xi'an, Shaan Xi of China. An online survey has been used to obtain feedback from 400 respondents. However, only 201 responseshave been returned and available for further analysis. This study discovers a beneficial connection between perceived ease of use, perceived usefulness and CAS use. This study could guide the accountants and business owners as well as the research communities to understand the correlation of technology acceptance and the use of CAS.
\end{abstract}

Index Terms: Computerised Accounting Systems, Perceived Ease of Use, Perceived Usefulness, Technology Acceptance Model (TAM), China

\section{INTRODUCTION}

Almost all of the accounting transactions currently are undergoing a transformation through digitalization. It is quite hard for us now to see the bookkeeping done manually. We can say now everything has been digitalized. The development of the computerized accounting systems (CAS) especially in the era of the industrial revolution (IR) 4.0 (or Industry 4.0) has become so important to be aligned with the development of the current technology such as cloud computing, internet of things, big data and analytics. As such, it is also quite substantial to understand the implementation of CAS among the accountants. For the purpose of this research, our scope is concentrated on China's micro and small enterprises (MSEs), specifically in Xi'an, China's Shaan Xi.
This research aims to further create understanding of the perceived ease of use, perceived usefulness, and use of CAS. This research also aims to broaden our knowledge of the connections between these variables with CAS, particularly in China's Xi'an, Shaan Xi. This paper addresses the following research questions:

RQ1: What is the relationship between perceived ease of use and the use of CAS?

RQ2: What is the relationship between perceived usefulness and the use of CAS?

This paper is organized as follows: in the next chapter, we first look at the literature review, which discusses the study's theoretical structure. Subsequently, in section 3, we develop the research hypotheses and research framework. Then, in section 4, we present our methodological approach for answering research questions. The results of the analysis were tabled in section 5 , and the results will be discussed further. In the final section, the summary of the study is presented, and the limitations and recommendations for further research are discussed.

\section{LITERATURE REVIEW}

The Technology Acceptance Model (TAM) is a technique proposed by Davis [1] to study the user's acceptance of the information system using rational behavior theory. The original purpose of the TAM is to describe the critical elements that are broadly acknowledged by the computer. TAM has been widely used in adoption research on information technology (IT). TAM is the theory of behavioral science, which argues about the impact of perceived ease of use and perceived usefulness on individuals' use of IT. According to Davis[1], the TAM introduces two significant factors: (1) the first factor is perceived usefulness (PU), reflecting the level at which individuals consider the use of a specific scheme to improve their efficiency, and (2) another factor is perceived ease of use (PEOU), reflecting the extent to which people believe it is simple to use a particular system (see Figure 1)[1]. 


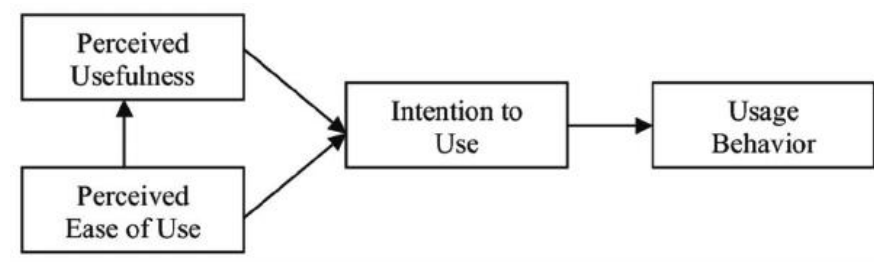

Fig. 1 Technology Acceptance Model[1]

The TAM believes that the use of the scheme is determined by the behavioral intent, and the behavioral intent is determined by the attitude towards use and the usefulness of perception, and the expected use is measured by the perceived usefulness and ease of use, perceived usefulness is determined by perceived ease of use and internal variables, and perceived ease of use is determined by internal variables[2]. The external variables include items such as system design features, user characteristics, execution process, policy impact, organizational structure while internal variables include the beliefs, attitudes, and intentions in the TAM and the differences between different individuals, environmental constraints, and controllable interference factors [2].

There were many studies adopted the TAM in the application of information systems research. For example, Dharmarajan and Gangadharan[3] explored TAM among nurses to determine the level of acceptance on nursing information systems in India and they found out that the respondents showed positive intention towards perceived usefulness, perceived ease of use and attitude towards the system. Bhatti[4] adopted an expanded TAM that involves perceived usefulness, perceived ease of use, personal innovativeness, subjective standards, behavioral control on acceptance of mobile commerce. They discovered that there are beneficial relationships between perceived ease of use, subjective norms, behavioral control, and mobile trade intention. They also discovered that behavioral control and subjective norms impact perceived ease of use, affecting user plans to adopt mobile commerce.

Rogers [5]investigates how small companies come to accept and use CAS in Central Ohio, United States. He discovered that there is a positive correlation between perceived ease of use, perceived usefulness, and the intention to adopt CAS. He also examines both CAS adopters and non-adopters and discovered that 5.9 percent of the variance attributed to perceived ease of use for adopters and 5.2 percent was attributed to perceived ease of use for non-adopters and 13.6 percent of the variance attributed to perceived usefulness for adopters and 24.7 percent was attributed to perceived usefulness for non-adopters. Thus, he concludes that perceived usefulness was more crucial to tiny companies that had not yet implemented CAS; however, perceived usefulness reduces in significance to about 2 percent once CAS is adopted. He also added that once tiny companies embrace CAS, ease of use becomes more essential and rises from $5.2 \%$ to $8.8 \%$.

Instead of TAM, many scientists have also embraced the Unified Theory of Technology Acceptance and Use (UTAUT). UTAUT is the TAM model evolution[6]. The UTAUTmodel (as shown in Figure 2) contains expected performance, expected effort, conditions facilitating, and social influence[7]. Gender, age, experience, and the volunteer to use are also affected by the intention to use.

Fowzia and Nasrin [8] explored the appreciation of CAS in financial institutions in Bangladesh. Using CAS, they use the UTAUT model to test performance expectancy, effort expectation, social influence, and social conditions. Their research discovered that with the use of CAS there is a important connection between performance anticipation, effort expectation, social impact and social conditions.

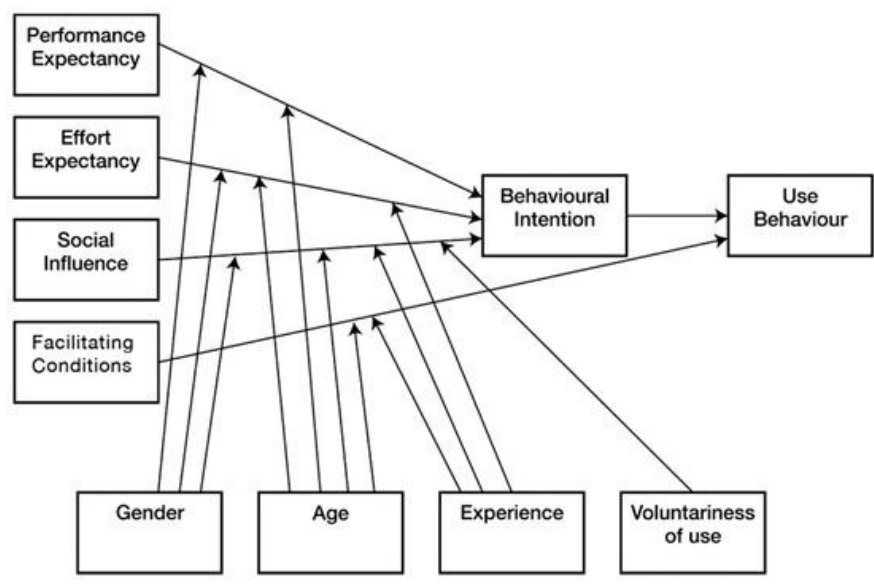

Fig. 2 The Unified Theory of Acceptance and Use of Technology (UTAUT) [7]

In the UTAUT model, performance expectations are individuals who believe that the use of the system can help them in the work performance receive a good mark. Performance anticipation remains equal to perceived usefulness, while effort expectation is the extent of a system's ease of use. It means that the expectation of effort is the same as ease of use in TAM. The UTAUT model is therefore also appropriate for this study. However, we focus on two TAM variables for this paper, perceived usefulness and perceived ease of use.

\section{RESEARCH FRAMEWORK}

In order to answer the research questions, the research framework as illustrated in Figure 3 is designed.

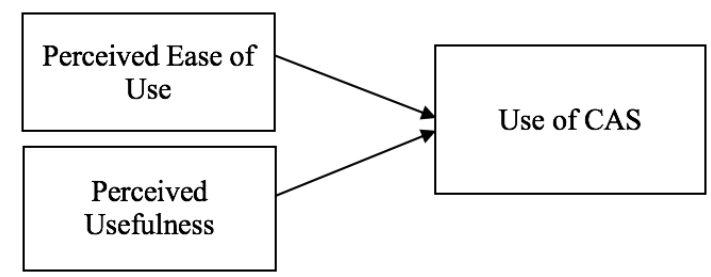

Fig. 3 Research Framework

\section{Perceived Ease of Use}

Perceived ease of use (PEOU) reflecting the extent to which a person believes it is easy to use a particular system [1]. User-centric conception is ease of use. There are many prior kinds of study believing that perceived ease of use has a important impact on IT customer reception and usage behavior[6]. 
Ozturk, Bilgihan, Nusair, and Okumus[9] specify the perceived ease of use as a self-determining factor to examine the impact on the mobile hotel booking loyalty intentions of users. They revealed that perceived ease of use had a significant impact on the mobile hotel booking technology loyalty intentions of the users. They also discovered that compatibility had a major effect on perceived ease of use and comfort, and perceived ease of use had a major effect on loyalty and comfort.

According to Wang and Ha-Brookshire [10], perceived ease of use relates to the extent to which the user believes that making use of particular technology would be effortless and hassle-free. They also found that within the Chinese textile and apparel company owners, perceived ease of use use with smooth relationships between the company's assets, employee abilities, and technology infrastructure.

Mustapha and Sheik Obid[11] evaluated the mediating impact of perceived ease of use on the connection between the quality of tax services and online tax tax in order to comprehend the efficient use of the online tax scheme by self-employed taxpayers in Nigeria. They discovered the connection between the quality of tax services and perceived ease of use to be important and perceived ease of use to be statistically positive with the online tax scheme.

In the context of CAS, the emergence of information technology changes the way on how the accounting transactions being recorded. Professional accountants need to know and learn to use a computer and understand on how to record the accounting transaction through CAS. The way on how it is recorded is different from the manual accounting system, and it is also varied among the types of CAS and the brand of accounting software itself. To some extent, the system developers need to understand the user expectation on how they perceive ease of use on the system. As such, perceived ease of use will influence the user's ability to use CAS. Therefore, it is hypothesised that

$\mathrm{H}_{1}$ : There is a positive relationship between perceived ease of use and the use of CAS by accountants in MSEs in Xi'an, Shaan Xi of China.

\section{Perceived Usefulness}

Davis [1] when proposing a technology acceptance model, defines cognitive usefulness as the extent to which aninformation system can assist in improving performance for users. Perceived usefulness relates to the degree to which the customer believes the technology will increase their efficiency on the job [1, 12 ]. Therefore, if someone is impressed when they used a specific system, they found that job performance to some extent has been improved, that means this system hasa greater influence of usefulness, and their attitude will change to a better direction [13]. While according to Mawhinney and Lederer [14],perceived usefulness is strongly related to user satisfaction.

Kapoor, Dwivedi, Piercy, Lal and Weerakkody[15] extend the TAM to investigate the aspects that influence the use of Radio Frequency Identification (RFID) in the library context. Their study finds that perceived usefulness, system value and users attitude have an optimistic effect on the use of the RFID services. Prieto, Migueláñez, and GarcíaPeñalvo[16] examine teachers ' attitude towards the use of was emphasized more on the effortlessness of technology

mobile technology using PLS-SEM methods. They proposed greater connections were developed between perceived usefulness and behavioral intention, perceived ease of use and perceived usefulness, and perceived self-efficacy and ease of use.

For the purpose of this paper, we are trying to examine the attitude of accountants regarding the use of CAS. As such, perceived usefulness will influence the user's use of CAS. So it is hypothesized that:

$\mathrm{H}_{2}$ : There is a positive relationship between perceived usefulness and the use of CAS by accountants in MSEs in Xi'an, Shaan Xi of China.

\section{METHODOLOGY}

This research primarily used an online survey to collect information from the participants. The reason for this research using online questionnaires is that it can shelter a large sample as well as provide adequate time for respondents to answer the questions to some extent.

The total of 400 accountants was called to join in this survey. After two months of the invitation with two reminders, 221 questionnaires were returned, representing $55.25 \%$ of the response rate. However, from all the returned questionnaire, 20 of them were incomplete and cannot be used for analysis. Therefore, only 201 questionnaires are usable and will be used for further analysis.

The questionnaire contains three sections. Section A is about the demographics. This section consists of ten questions which can answer into relevant research questions. Through this section, the current state of CAS usage by MSEs in Xi'an, Shaan Xi of China can be explored. Three questions focus on the respondent profile and seven questions on the firms' demographic profile. Section B is about the usage of CAS. This section contains six questions. If the respondent answers their company to implement the CAS, they can answer this part. This section tries to investigate the basic types of CAS in MSEs in Xi'an, Shaan $\mathrm{Xi}$ of China.

In section $\mathrm{C}$, the questions were designed to investigate the features that influence the usage of CAS. The question in this section was adapted from Rogers [6] who investigate small companies' adoption of CAS in Central Ohio, United States. This section has 16 questions. Questions C1 to C7 measure the perceived independent variable ease of use, question $\mathrm{C} 8$ to $\mathrm{C} 12$ measure the perceived independent variable usefulness and question $\mathrm{C} 13$ to $\mathrm{C} 16$ measure the dependent variable of use of CAS. Every item is evaluated using a seven-point Likert scale where $1=$ strongly disagree, 2 = moderately disagree, $3=$ somewhat disagree, $4=$ neutral, $5=$ somewhat agree, $6=$ moderately agree, $7=$ strongly agree.

\section{RESULTS}

\section{Data Screening}

Before the data have been further analysed, data screening needs to be conducted. 
For this research, only completed questionnaire have been used for further analysis. So, there is no missing data. Missing data frequently happen when the respondent not able to completely reply questions in a survey [17].

\section{Validity Test}

Validity refers to the trustworthiness of the research design being used, with high validity, usually producing correct and meaningful results. However, there is no distinctive measure of the validity of a scale. Research surveys have three kinds of validity such as content validity, criterion validity, and construct validity [18]. Content validity means that how a scale or measure has adequately sampling from the entire content. Criterion validity deals with the association that exists between the scale scores and some detailed, measurable standard. Construction validity has to do with testing a scale on the nature of the fundamental variable or construct, but this test was conducted during the pilot study.

\section{Reliability Test}

The reliability referred that the degree to which consequences are steady over time. Reliability is required of research studied. If the outcomes of research can be replicated in an analogous approach, the research instrumentation is reflected to be reliable [19]. This study uses a coefficient alpha to estimate internal consistency reliability.

Cronbach's alpha, which is also known as alpha reliability is a method of examining the reliability [20]. It is the most commonly used in social science research. The researcher used this method to examine the internal consistency of the items. The Cronbach's Alpha for this study is 0.904, which is statistically reliable for us to proceed with the analysis.

\section{Factor Analysis}

In the study of practical problems, multivariate problems are often encountered. Too many variables will undoubtedly increase the difficulty and complexity of analysing the problem, and in many practical problems, there are several variables that have the relevant relationship. People would have believed that, based on the appropriate assessment, it would be feasible to replace the ancient variables with fewer fresh variables and to maintain as many of the new variables as possible to maintain the data expressed by the original variables. So, factor analysis has been developed. Factor analysis as a method that has been used to decrease a good deal of variables into small as well as a better manageable number of factors [21]. There are 16 items been collected to predict the intention to use the CAS in micro and small businesses. Based on the information gathered from the respondents, the investigator began to conduct the factor analysis to recognize the underlying variables.
KMO and Bartlett's test needed to be measured before factor analysis has been conducted. The value of KMOranges from 0 and 1.If the KMOvalue is closer to 1, it suggests the higher the relevant variables, and the more appropriate for factor examination. However, if the value of $\mathrm{KMO}$ is closer to 0 , it reveals the lower the relationship of the variables and the less appropriate for the factor analysis. Bartlett (1951) proposed a spherical test for the interrelated correlation matrix. Kaiser, Meyer, and Olkin suggest the guideline for assessing the measure of KMO value. The value of KMOmust be at least 0.60, and Bartlett's test of sphericity, which is to test the significant relationship must be below 0.05 [22]. The test for the KMO and Bartlett's is presented in Table 1. It indicates that factor analysis can proceed.

Table. 1 KMO and Bartlett's Test

\begin{tabular}{|c|c|c|}
\hline $\begin{array}{c}\text { Kaiser-Meyer-Olkin } \\
\text { Adequacy. }\end{array}$ & .913 \\
\hline $\begin{array}{c}\text { Bartlett's Test of } \\
\text { Sphericity }\end{array}$ & Approx. Chi-Square & 1235.8 \\
& df & 120 \\
\cline { 2 - 3 } & Sig. & .000 \\
\hline
\end{tabular}

The principal component analysis is an exploratory technique that is necessary to analyse. In multivariate regression, principal component analysis can help determine whether there is collinearity and can also be used to deal with collinearity [23].Hair et al.[23] suggested that when the researcher does the factor analysis, the eigen values of less than 1 will be rejected and factors with eigenvalue more than 1.0 are revealed to be significant and sustained for advanced analysis. This procedure is in agreement with Harman's single factor analysis[24 ] which involves loading all the variables of the constructs simultaneously into an exploratory factor analysis and examining the unrotated factor solution to determine the number of factors necessary to account for the variance in the variables. In determining the existence of CMV, the primary assumption states that "if there is a substantial amount of CMV, the factor analysis results could either be a single factor or that the majority of the covariance in the dependent and independent variables is caused by a single factor"[25].

Following, an un-rotated exploratory factor analysis of all the study items exhibited 3 component factors in total, which explains 55.42 per cent of the variance. The result of the total variance extracted is presented in Table 2. Granting that a single factor solution did not emerge, and a general factor is not reflected for most of the variance, common method variance is not regarded as a significant threat in this research [24].

Table. 2 Total Variance Explained

\begin{tabular}{|c|c|c|c|c|c|c|}
\hline \multirow{2}{*}{ Component } & \multicolumn{3}{|c|}{ Initial Eigenvalues } & \multicolumn{3}{|c|}{ Extraction Sums of Squared Loadings } \\
\hline & Total & $\%$ of Variance & Cumulative $\%$ & Total & $\%$ of Variance & Cumulative $\%$ \\
\hline 1 & 6.594 & 41.214 & 41.214 & 6.594 & 41.214 & 41.214 \\
\hline
\end{tabular}




\begin{tabular}{lllllll}
\hline 2 & 1.210 & 7.561 & 48.775 & 1.210 & 7.561 & 48.775 \\
3 & 1.063 & 6.645 & 55.420 & 1.063 & 6.645 & 55.420 \\
4 & .937 & 5.858 & 61.278 & & & \\
5 & .820 & 5.124 & 66.402 & & \\
6 & .699 & 4.367 & 70.768 & & \\
7 & .642 & 4.012 & 74.781 & & \\
8 & .594 & 3.711 & 78.492 & & \\
9 & .571 & 3.567 & 82.059 & & \\
10 & .531 & 3.317 & 85.376 & & \\
11 & .476 & 2.972 & 88.348 & & \\
12 & .457 & 2.857 & 91.205 & & \\
13 & .392 & 2.453 & 93.657 & & \\
14 & .388 & 2.424 & 96.081 & & \\
15 & .334 & 2.089 & 98.170 & & \\
16 & .293 & 1.830 & 100.000 & & \\
\hline
\end{tabular}

\section{Descriptive Statistics}

Before the descriptive analysis, the researcher first runs the dimension analysis in IBM SPSS version 22. Based on dimensional analysis, dependent variable (use of CAS) and autonomous variables (perceived ease of use and perceived usefulness) were obtained. Table 3 summaries the statistics result. The descriptive statistics of the intention to use, which reveals a mean value of 5.74 (standard deviation, $0.655)$, is the highest of the remaining three constructs' mean.

In addition, the descriptive analysis shows that the perceived ease of use has the lowest mean value of 5.38 (standard deviation, 0.717) in comparison with other independent construct variables of Perceived usefulness mean value of 5.61 (standard deviation, 0.665).
Table. 3 Descriptive Statistics

\begin{tabular}{|c|c|c|c|c|}
\hline Variables & $\mathbf{N}$ & Min & MaxMean & $\begin{array}{l}\text { Std. } \\
\text { Deviation }\end{array}$ \\
\hline $\begin{array}{l}\text { Perceived } \mathrm{H} \\
\text { Use }\end{array}$ & $\mathrm{f} 201$ & 2.71 & 6.575 .3788 & .71668 \\
\hline $\begin{array}{l}\text { Perceived } \\
\text { Usefulness }\end{array}$ & 201 & 3.60 & 7.005 .6129 & .66455 \\
\hline Use of CAS & 201 & 3.75 & 7.005 .7413 & 65497 \\
\hline
\end{tabular}

\section{Hierarchical Multiple Regression Analysis}

Multivariate regression analysis relates to the technique of predicting the model by creating the correlation between 2 or several independent variables as well as a dependent variable [26]. The goal of the experiment was to determine whether there was a linear connection between the independent variables (perceived ease of use and perceived usefulness) and the dependent variable (use of CAS) as described in Table 4, Model Summary.

Table. 4 ModelSummary ${ }^{\mathrm{c}}$

\begin{tabular}{|c|c|c|c|c|c|c|c|c|c|c|}
\hline \multirow[t]{2}{*}{ Model } & \multirow[t]{2}{*}{$\mathbf{R}$} & \multirow{2}{*}{\multicolumn{2}{|c|}{\begin{tabular}{|l|l} 
R Square & $\begin{array}{l}\text { Adjusted } \\
\text { Square }\end{array}$ \\
\end{tabular}}} & \multirow{2}{*}{ 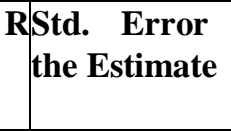 } & \multicolumn{5}{|c|}{ of Change Statistics } & \multirow{2}{*}{$\begin{array}{l}\text { Durbin- } \\
\text { Watson }\end{array}$} \\
\hline & & & & & \begin{tabular}{|l|} 
R \\
Change
\end{tabular} & \begin{tabular}{l|l|} 
Square Change & Chat
\end{tabular} & df1 & df2 & Sig. F Change & \\
\hline 1 & $.654^{\mathrm{a}}$ & .427 & .425 & .49685 & .427 & 148.551 & 1 & 199 & .000 & 2.066 \\
\hline 2 & $.744^{\mathrm{b}}$ & .554 & .551 & .43869 & .554 & 246.818 & 1 & 199 & .000 & 2.178 \\
\hline
\end{tabular}

a. Predictors: (Constant), PEOU (Perceived Ease of Use)

b. Predictors: (Constant), PU (Perceived Usefulness)

c. Dependent Variable: Use of CAS

\section{Step 1 - Assessing the model of the study}

In evaluating the research model, we check the R Square values during the first Model Summary box. After entering the variables in Block 1, Perceived ease of use, the general model describes 42.7 percent of the variance $(.0427 \mathrm{x} 100)$. We also include Block 2 variables that are perceived ease of use, perceived usefulness and use of CAS, the model as a whole explains 55.4 percent (.554 x 100). In addition, we look at the column labeled R Square shift to find out how much of this general variance is explained by the dependent variable, Use of CAS. The shift value of R Square is .554. It therefore shows which Perceived Usefulness or Use of CAS explains an additional 55.4 percent $(.554 \mathrm{x} 100)$ of the variance in use of CAS, while the effects of Perceived Ease of Use Response are statistically accounted for. It is also a statistically significant contribution when supported by Sig. Change the value of this line (.000). In addition, we test the Durbin-Watson Value, which is used to verify whether there is autocorrelation in the residual with the appropriate range 1.5 to 2.5 benchmark criteria. The Durbin-Watson value 2.066 from Block 1 (i.e. perceived ease of use) is within the appropriate range in the research. So, it implies there are no problems of autocorrelation. Similarly, the Durbin-Watson value of 2,178 from Block2 variables perceived ease of use, perceived usefulness and use of CAS, the model as a whole as displayed in Table 4, Model overview falls within the acceptable range and is therefore an indication of no autocorrelation problems[27]. 
Perceived Ease of Use, Perceived Usefulness and the Usage of Computerized Accounting Systems: A Performance of Micro and Small Enterprises (MSEs) in China

We evaluated the statistical significance of the result outlined in Table 5. Anova is the variance analysis to be tested for the mean difference of two or more samples[28]. It tests the null hypothesis that various $\mathrm{R}$ in the population is equal to 0 . In this research, the model reaches statistical importance (i.e. Sig.=.000; this really implies $\mathrm{p}<.0005$ ) with a F value of 153.699. The null hypothesis is therefore dismissed. At least one independent variable has a major impact on the dependent variable. It implies that perceived ease of use and perceived usefulness were excellent forecasters for the use of computerized accounting systems. The Anova as demonstrated by Table 5 shows that the model which includes the two Blocks of variables (i.e., Blocks 1 and 2) is significant $(F(1,199)=153.699, p<$ .0005).

Table. 5 Anova ${ }^{c}$

\begin{tabular}{|l|l|l|l|l|}
\hline Model & $\begin{array}{l}\text { Sum of df } \\
\text { Squares }\end{array}$ & $\begin{array}{l}\text { Mean } \\
\text { Square }\end{array}$ & F & Sig. \\
\hline
\end{tabular}

\begin{tabular}{|l|l|l|l|l|l|}
\hline Regression & 16.672 & 1 & 16.672 & 48.046 & $.000^{\mathrm{a}}$ \\
1 Residual & 69.125 & 199 & .347 & & \\
Total & 85.797 & 200 & & & \\
\hline Regression & 35.197 & 1 & 35.197 & 153.699 & $.000^{\mathrm{b}}$ \\
2 Residual & 45.600 & 199 & .229 & & \\
Total & 85.797 & 200 & & & \\
\hline
\end{tabular}

a. Predictors: (Constant), PEOU (Perceived Ease of Use)

b. Predictors: (Constant), PU (Perceived Usefulness)

c. Dependent Variable: Use of CAS.

\section{Step 2 - Evaluating each of the independent variables}

In this study, we find out how well each of the independent variables contributes to the final equation by analysing the coefficients, as reflected in Table 6 Model 2 row. From the Sig. column, there are two variables that make a unique statistically significant contribution (i.e., less than .005). We list in order of importance based on the beta value, perceived usefulness $($ Beta $=.557)$ and perceived ease of use $($ Beta $=.276)$.

Table. 6 Coefficients ${ }^{\mathrm{a}}$

\begin{tabular}{|c|c|c|c|c|c|c|c|}
\hline \multirow[t]{2}{*}{ Model } & \multicolumn{2}{|c|}{$\begin{array}{l}\text { Unstandardized } \\
\text { Coefficients }\end{array}$} & \multirow{2}{*}{\begin{tabular}{|l|} 
Standardized \\
Coefficients \\
Beta \\
\end{tabular}} & \multirow[t]{2}{*}{$\mathbf{t}$} & \multirow[t]{2}{*}{ Sig. } & \multicolumn{2}{|c|}{ Collinearity Statistics } \\
\hline & B & Std. Error & & & & \begin{tabular}{|l|l|} 
Tolance \\
\end{tabular} & VIF \\
\hline 2 (Constant) & 1.303 & .262 & & 4.973 & .000 & & \\
\hline PEOU & .253 & .056 & .276 & 4.495 & .000 & .541 & 1.850 \\
\hline PU & .549 & .061 & .557 & 9.050 & .000 & .541 & 1.850 \\
\hline
\end{tabular}

a. Dependent Variable: Use of CAS

We also used cut-off points to determine the existence of multicollinearity (i.e., a tolerance value below.10, or a VIF value above 10) as shown in Table 6, Coefficients. In this research, the tolerance value for each independent variable is.541, which is not less than.10; therefore, there is no breach of multicollinearity hypothesis. Also, the VIF value, which is 1.850 and well below the 10 cut-off, supports nonviolation. These results are not surprising, as the Pearson correlation coefficient between these two independent variables was only.678 or.68 (see Correlation Table 7).

Similarly, we compare the various variables by looking at the standardized coefficients, not the unstandardized ones in Table 6. Standardized connotations that the values were converted to the same scale for each of the distinct variables to improve contribution comparison. To do this, we look at the Beta column and discover the largest beta value is .557 or .56, which is for perceived usefulness (PU). This means that PU makes the greatest distinctive contribution to explaining the dependent variable when controlling the variance described by all other variables in the model. The beta value for PEOU was smaller (.276 or.28), suggesting it made less of a distinctive contribution. Furthermore, we look at the column marked Sig. which reveals whether this variable is making a statistically significant unique contribution to the prediction of the dependent variable, USE. To test the robustness of the model results, the researcher uses the unstandardized (B) coefficients(with their standard errors) as in Table 6 to construct a regression equation as follows:

Use of CAS $=1.303+0.056$ (Perceived ease of use) +0.061 (Perceived usefulness $)+\varepsilon$
Table. 7 Correlations

\begin{tabular}{|cl|l|l|l|}
\hline & USE & PEOU & PU \\
\hline USE & $\begin{array}{l}\text { Pearson } \\
\text { Correlation } \\
\text { Sig. (1-tailed) }\end{array}$ & 1 & 0.654 & 0.744 \\
N & 201 & 0 & 0 \\
\hline PEOUPearson & 0.654 & 1 & 0.678 \\
& $\begin{array}{l}\text { Correlation } \\
\text { Sig. (1-tailed) } \\
\text { N }\end{array}$ & 0 & & 0 \\
\hline PU & $\begin{array}{l}\text { Pearson } \\
\text { Correlation } \\
\text { Sig. (1-tailed) } \\
\text { N }\end{array}$ & 0.744 & 0.678 & 1 \\
\hline
\end{tabular}

\section{Results of Hypothesis Testing}

Based on the study structure and the creation of hypotheses, we used hierarchical multiple regression analysis to examine the connection between and between the factors as described in this studies.

This research specifically uses the linear regression analysis to examine whether perceived ease of use has an influence on the Use of CAS among MSEsin Xi'an, Shaan $\mathrm{Xi}$ of China. Table 4, the Model summary, shows that the Model 1 (PEOU and USE) explains 42.7 percent $(.472 \mathrm{x}$ $100)$ of the variance, $R$ squared value. 
Similarly, the Model 2 (PEOU, PU and USE), taken holistically explains 55.7 percent $(.557 \times 100)$ of the variance, $R$ squared value. Thus, the models have a statistically significant contribution as indicated in Table 4 by the Sig. F change value for these lines (.000).

As revealed in Table 4, the Model 1 (i.e. PEOU and USE) is significant $(\mathrm{F}(1,199)=148.55, \mathrm{p}<.0005)$ while Model 2 (i.e. PEOU and PU) taken as a whole is significant ( $F(1$, 199) $=246.82, \mathrm{p}<.0005)$.

Furthermore, the results of all the hypotheses are as contained in Table 5, Anova ${ }^{c}$. The results of hypothesis testing Model 1 shown in Table 5 provides the conclusion that perceived ease of use significantly influence the high level of the use of CAS by accountants in MSEs in Xi'an, Shaan Xi of China with F change $(1,199)=48.05, \mathrm{p}<.001$. By this finding, the hypothesis H1, which states: There is a positive relationship between perceived ease of use and the use of CAS by accountants in MSEs in Xi'an, Shaan Xi of China is thus supported and confirmed.

The results of hypothesis testing Model 2 shown in Table 5 provides the conclusion that perceived usefulness significantly impact the level of use of CAS by accountants in MSEs in Xi'an, Shaan Xi of China with F change $(1,199)$ $=153.70, \mathrm{p}<.001$. By this finding, the hypothesis $\mathrm{H} 2$, which states: There is a positive significant relationship between perceived usefulness and the use of CAS by accountants in MSEs in Xi'an, Shaan Xi of China is validly supported and confirmed.

Summary of the Results from Hierarchical Multiple RegressionHierarchical multiple regression was used to evaluate the ability of two independent variables (PEOU, PU) to predict the dependent variable (Use of CAS). We conduct a preliminary analysis to ensure no violation of the assumptions of normality, linearity, multicollinearity and homoscedasticity. Perceived ease of use was entered at Model 1, explaining 42.7 per cent of the variance in the Use of CAS. After entry of the perceived ease of use and perceived usefulness at Model 2, the total variance explained by the model as a whole was 55.4 percent, F (1, $199)=153.70, p<.001$. The two variables (i.e. PEOU and PU) explained an additional 55.4 percent of the variance in USE, R squared change $=.55$, F change $(1,199)=246.82, p$ $<.001$. In the final model, the two control measures were statistically significant, with Perceived Usefulness recording a higher beta value $(\beta=.58, p<.001)$ than the Perceived ease of use, $\operatorname{PEOU}(\beta=.28, \mathrm{p}<.001)$.

\section{CONCLUSIONS}

Based on 201 feedback from the respondents in China's MSEsin Xi'an Shaan Xi, this study finds that perceived ease of use and perceived usefulness has a beneficial impact on the use of CAS. Through the multiple regression analysis, this study finds that there is a positive association between perceived ease of use and perceived usefulness with the intention of using CAS. The primary goal of this study was thus accomplished and the research questions highlighted in the first chapter were answered. About the current usage state of CAS in Xi'an, Shaan Xi of China, there were about the $73.6 \%$ of business already implemented CAS while $26.4 \%$ of the business still did not implement CAS in Xi'an,

Shaan Xi of China[29]. The findings also indicate that the perceived ease of use influenced the use of CAS by 42.7 percent. Perceived usefulness confirms 55.4 percent impact on CAS use. The combination of perceived ease of use and perceived usefulness affects the use of CAS by 49.05 percent.

This study may help accountants and business owners understand the correlation between technology acceptance and the use of CAS, especially in the MSEs, which could probably help them to succeed in their business.

There are several constraints in this research. The first restriction concerns the sample size. The total number of invitations sent to participate in this survey was 400 . However, 221 questionnaires were returned, and only 201 were used for further analysis. The respondent rate represents $55.25 \%$. Although the number of questionnaires returned is enough to do the analysis, however, compare to the number of populations in Xi'an, it is relatively small.

Secondly, the collection of data was retrieved from the sample of MSEsonly and not from the larger businesses. Future research could expand the study into medium and large businesses.

Thirdly, this research uses an online survey. This approach can acquire a situation or an event at a given time. Future study can use other research approaches such as observations, experiments or case study. These methods probably can give us a more detailed explanation of the adoption of CAS.

\section{REFERENCES}

1. F. D. Davis, "Perceived Usefulness, Perceived Ease of Use, and User Acceptance of Information Technology," MIS Q., vol. 13, no. 3, p. 319, Sep. 1989.

2. Venkatesh and F. D. Davis, "A Theoretical Extension of the Technology Acceptance Model: Four Longitudinal Field Studies," Manage. Sci., vol. 46, no. 2, pp. 186-204, Feb. 2000.

3. B. Dharmarajan and K. Gangadharan, "Applying Technology Acceptance (TAM) Model to Determine the Acceptance of Nursing Information System (NIS) for Computer Generated Nursing Care Plan among Nurses," Int. J. Comput. Trends Technol. 2, vol. 4, no. 8, pp 2625-2629, 2013.

4. T. Bhatti, "Exploring Factors Influencing the Adoption of Mobile Commerce," J. Internet Bank. Commer., vol. 12, no. 3, pp. 1-13, 2007.

5. Rogers, "Examining Small Business Adoption of Computerized Accounting Systems Using the Technology Acceptance Model.," Walden University, 2016.

6. V. Venkatesh, "Determinants of Perceived Ease of Use: Integrating Control, Intrinsic Motivation, and Emotion into the Technology Acceptance Model," Inf. Syst. Res., vol. 11, no. 4, pp. 342-365, Dec. 2000.

7. V. Venkatesh, M. G. Morris, G. B. Davis, and F. D. Davis, "User Acceptance of Information Technology: Toward a Unified View," MIS $Q$., vol. 27, no. 3, p. 425, 2003.

8. R. Fowzia and M. Nasrin, "Appreciation of Computerized Accounting System in Financial Institutions in Bangladesh," World Rev. Bus. Res., vol. 1, no. 2, pp. 1-9, 2011.

9. B. Ozturk, A. Bilgihan, K. Nusair, and F. Okumus, "What keeps the mobile hotel booking users loyal? Investigating the roles of selfefficacy, compatibility, perceived ease of use, and perceived convenience," Int. J. Inf. Manage., vol. 36, no. 6, pp. 1350-1359, Dec. 2016 . 
10. Wang and J. Ha-Brookshire, "Perceived Usefulness and Perceived Ease of Use of New Technologies Described by Chinese Textile and Apparel Firm Owners and Managers," in International Textile and Apparel Association (ITAA) Annual Conference Proceedings, 2018, pp. 1-3.

11. Mustapha and S. N. Sheikh Obid, "Tax Service Quality: The Mediating Effect of Perceived Ease of Use of the Online Tax System," Procedia Soc. Behav. Sci., vol. 172, pp. 2-9, Jan. 2015.

12. Sledgianowski and S. Kulviwat, "Using Social Network Sites: The Effects of Playfulness, Critical Mass and Trust in a Hedonic Context," J. Comput. Inf. Syst., vol. 49, no. 4, pp. 74-83, 2009.

13. Robey, "User Attitudes and Management Information System Use," Acad. Manag. J., vol. 22, no. 3, pp. 527-538, Sep. 1979.

14. C. H. Mawhinney and A. L. Lederer, "A study of personal computer utilization by the manager," Inf. Manag., vol. 18, pp. 243-253, 1990.

15. K. Kapoor, Y. Dwivedi, N. C. Piercy, B. Lal, and V. Weerakkody, "RFID integrated systems in libraries: extending TAM model for empirically examining the use," J. Enterp. Inf. Manag., vol. 27, no. 6, pp. 731-758, Oct. 2014.

16. J. C. Sánchez-Prieto, S. Olmos-Migueláñez, and F. J. García-Peñalvo, "MLearning and pre-service teachers: An assessment of the behavioral intention using an expanded TAM model," Comput. Human Behav., vol. 72, pp. 644-654, Jul. 2017.

17. R. Little and D. Rubin, Statistical analysis with missing data. John Wiley \& Sons., 2014.

18. G. Marczyk, D. DeMatteo, and D. Festinger, Essentials of research design and methodology. Hoboken, NJ, US: John Wiley \& Sons Inc., 2005.

19. E. Bell, A. Bryman, and B. Harley, Business research methods. Oxford University Press, 2015.

20. L. J. Cronbach, "Coefficient alpha and the internal structure of tests," Psychometrika, vol. 16, no. 3, pp. 297-334, Sep. 1951.

21. J. Pallant, SPSS Survival Manual: A step by step guide to data analysis using SPSS for Windows (Version 10). Buckingham, Philadelphia: Open University Press, 2013

22. S. Beavers, J. W. Lounsbury, J. K. Richards, S. W. Huck, G. J. Skolits, and S. L. Esquivel, "Practical Considerations for Using Exploratory Factor Analysis in Educational Research," Pract. Assessment, Res. Eval., vol. 18, no. 6, pp. 1-13, 2013.

23. J. Hair, R. Anderson, B. Babin, and W. Black, Multivariate data analysis: A global perspective (Vol. 7). Upper Saddle River, NJ: Pearson, 2010

24. P. M. Podsakoff and D. W. Organ, "Self-reports in organizational research: Problems and prospects," J. Manage., vol. 12, no. 4, pp. 531$544,1986$.

25. P. M. Podsakoff, S. B. MacKenzie, J.-Y. Lee, and N. P. Podsakoff, "Common method biases in behavioral research: A critical review of the literature and recommended remedies.," J. Appl. Psychol., vol. 88, no. 5 , p. 879, 2003.

26. P. Cohen, P. Cohen, S. G. West, and L. S. Aiken, Applied Multiple Regression/Correlation Analysis for the Behavioral Sciences. New York: Psychology Press, 2014.

27. S. V. C. de Souza and R. G. Junqueira, "A procedure to assess linearity by ordinary least squares method," Anal. Chim. Acta, vol. 552, no. 1-2, pp. 25-35, Nov. 2005.

28. M. W. Lipsey and D. B. Wilson, Applied social research methods series; Vol. 49. Practical meta-analysis. Thousand Oaks, CA, US: Sage Publications, Inc., 2001.

29. Z. Lanlan and A. Ahmi, "Exploration on the Use of Computerized Accounting Systems by Micro and Small Enterprises (MSEs) in China," Int. J. Eng. Technol., vol. 7, no. 3.2, pp. 806-810, 2018. 